\title{
Vaccine Development Total
}

National Cancer Institute

\section{Source}

National Cancer Institute. Vaccine Development Total. NCI Thesaurus. Code C19457.

Any aspect of vaccine research, development, testing, etc., for diseases other than AIDS. A vaccine must involve the administration of an antigen to induce an active and specific immune response. Induction of passive immunity does not constitute a vaccine although the term is sometimes misused for this process. 